\title{
Randomized controlled trial of ragweed sublingual immunotherapy tablet in the subpopulation of Canadian children and adolescents with allergic rhinoconjunctivitis
}

\author{
Anne K. Ellis ${ }^{1 \dagger}$, Remi Gagnon ${ }^{2 \dagger}$, David I. Bernstein ${ }^{3}$ and Hendrik Nolte ${ }^{4^{*}}$
}

\begin{abstract}
Background: Post hoc analyses of randomized placebo-controlled trials have demonstrated efficacy and tolerability of the ragweed sublingual immunotherapy (SLIT)-tablet in Canadian adults with ragweed pollen-induced allergic rhinitis/conjunctivitis (AR/C). This post hoc analysis evaluated the efficacy and tolerability of the ragweed SLIT-tablet in the subpopulation of Canadian children and adolescents with AR/C in a previously described randomized, doubleblind, placebo-controlled trial.
\end{abstract}

Methods: The trial (NCT02478398) was conducted in North American and European children/adolescents ages 5-17 years with ragweed pollen-induced AR/C with or without asthma ( $\mathrm{FEV}_{1} \geq 80 \%$ predicted). Participants were randomized to daily ragweed SLIT-tablet (12 Amb a 1-U) or placebo for up to 28 weeks. The primary endpoint was the average total combined score (TCS; sum of rhinoconjunctivitis daily symptom score [DSS] and daily medication score [DMS]) during peak ragweed pollen season (RPS). Key secondary endpoints were TCS during the entire RPS, and DSS and DMS during peak RPS. Post hoc analyses of the primary and key secondary endpoints were conducted in the subpopulation of Canadian participants.

Results: Of the 1025 randomized participants, 246 (SLIT-tablet, $n=116$; placebo, $n=130$ ) were in the Canadian subpopulation. In the total study population, relative TCS ( $95 \% \mathrm{Cl}$ ) improvement with ragweed SLIT-tablet versus placebo was $-38.3 \%$ ( $-46.0 \%,-29.7 \%$; least square $[L S]$ mean difference, $-2.73 ; P<0.001)$ during peak RPS. In the Canadian subpopulation, relative TCS improvements with ragweed SLIT-tablet versus placebo were - $40.8 \%$ $(-54.5 \%,-20.2 \%$; LS mean difference, $-1.59 ; P=0.001)$ during peak RPS and $-36.6 \%(-50.2 \%,-16.5 \%$; LS mean difference, $-1.36 ; \mathrm{P}=0.002$ ) during the entire RPS. DSS and DMS during peak RPS in the Canadian subpopulation improved with SLIT-tablet versus placebo by $-30.6 \%(-45.2 \%,-7.7 \%$; LS mean difference, $-0.94 ; \mathrm{P}=0.010)$ and $-77.2 \%(-97.5 \%,-44.2 \%$; LS mean difference, $-0.66 ; P=0.003)$, respectively. No events of anaphylaxis, airway compromise, intramuscular epinephrine administration, eosinophilic esophagitis, or severe treatment-related systemic allergic reactions were reported in the overall population or Canadian subpopulation.

Conclusion: Efficacy and safety of the ragweed SLIT-tablet in Canadian children/adolescents with ragweed pollen-induced AR/C was consistent with the total study population. The ragweed SLIT-tablet resulted in clinically

\footnotetext{
*Correspondence: Hendrik.nolte@alk.net

${ }^{\dagger}$ Anne K. Ellis and Remi Gagnon contributed equally to this work

${ }^{4}$ ALK, Bedminster, NJ, USA

Full list of author information is available at the end of the article
} permits use, sharing, adaptation, distribution and reproduction in any medium or format, as long as you give appropriate credit to the original author(s) and the source, provide a link to the Creative Commons licence, and indicate if changes were made. The images or other third party material in this article are included in the article's Creative Commons licence, unless indicated otherwise in a credit line to the material. If material is not included in the article's Creative Commons licence and your intended use is not permitted by statutory regulation or exceeds the permitted use, you will need to obtain permission directly from the copyright holder. To view a copy of this licence, visit http://creativecommons.org/licenses/by/4.0/. The Creative Commons Public Domain Dedication waiver (http://creativeco mmons.org/publicdomain/zero/1.0/) applies to the data made available in this article, unless otherwise stated in a credit line to the data. 
meaningful improvement in symptoms, decreased symptom-relieving medication use, and was well tolerated in Canadian children/adolescents.

Trial registration: clinicaltrials.gov, NCT02478398. Registered June 23, 2015, https://clinicaltrials.gov/ct2/show/NCT02 478398?term $=$ NCT02478398\&draw $=2 \&$ rank $=1$

Keywords: Ragweed, Children, Adolescents, Allergic rhinoconjunctivitis, Sublingual immunotherapy

\section{Introduction}

Allergic rhinitis/conjunctivitis (AR/C) can cause a substantial burden on children and adolescents, interfering with sleep and daily activities, as well as negatively impacting school attendance and performance [1, 2]. Ragweed pollen is a common reported cause of $A R / C$ and sensitization to ragweed has increased as the plant distribution has spread [2-4]. Although published data on the sensitization to ragweed in Canada is generally lacking, the average prevalence of ragweed sensitization in adults in the general population across Canada was $15 \%$, but was as high as $33 \%$ in Montreal [5]. A small $(\mathrm{N}=39)$, singlesite study of 6-year old Canadian children indicated that $15 \%$ were sensitized to ragweed (unpublished observations, Anne K. Ellis). In the US, 11\% of children ages $6-9$ years and $19 \%$ of children and adolescents ages 10-19 years are sensitized to ragweed [6].

Allergy immunotherapy (AIT) delivered either by subcutaneous injection (SCIT) or sublingual tablets is a recommended treatment for $\mathrm{AR} / \mathrm{C}$ [7]. Unlike symptom-relieving medications, AIT is diseasemodifying with persisting effects and the potential to prevent the development of allergic asthma in children $[8,9]$. The sublingual immunotherapy (SLIT)-tablet form of AIT administration is an appealing alternative to SCIT for children, adolescents, and their caregivers because it can be self-administered at home after the first dose, it avoids the need for repeat injections, and it has a better safety profile than SCIT [10-12].

Post hoc analyses of randomized, double-blind, placebo-controlled trials $[13,14]$ have demonstrated the efficacy and tolerability of the $12 \mathrm{Amb}$ a 1-U ragweed SLIT-tablet (Ragwitek/Ragwizax, ALK, Hørsholm, Denmark) in Canadian adults with ragweed polleninduced AR/C [15]. The objective of this post hoc analyses of a previously described randomized, doubleblind, placebo-controlled trial [16] of the ragweed SLIT-tablet conducted in children and adolescents was to determine the efficacy and tolerability of the ragweed SLIT-tablet in the subpopulation of Canadian children and adolescents.

\section{Methods}

Details of the original randomized, double-blind, placebo-controlled, phase 3 trial (P008; clinicaltrials. gov identifier NCT02478398; EudraCT: 2014-00434127) conducted in North America and Europe have been previously reported [16]. Briefly, participants aged 4 to 17 years with a history of physician-diagnosed ragweed pollen-induced $\mathrm{AR} / \mathrm{C}$ with or without asthma (forced expiratory volume in $1 \mathrm{~s} \geq 80 \%$ ) were randomized 1:1 to once-daily ragweed SLIT-tablet (12 Amb a 1-U dose; ALK, Hørsholm, Denmark) or placebo. To complete the enrollment goal, 3 separate cohorts were recruited over 3 consecutive (2016-2018) ragweed pollen seasons (RPS). Treatment was started approximately 12 to 20 weeks before the RPS and continued for the duration of the season (approximately 8 weeks). The first dose was administered at the study site and subsequent doses were administered at home. Open-label symptomrelieving medication was provided to all participants (see Additional file 1: Table S1) and a short-acting betaagonist was provided to participants with asthma. Selfinjectable epinephrine was provided at 2 sites in Canada per Institutional Review Board request.

The study was approved by each sites' Institutional Review Board and was conducted in compliance with the Declaration of Helsinki and Good Clinical Practice. The guardian of each participant provided written informed consent before the participant started the trial.

\section{Ragweed pollen season}

The RPS for each study site was defined as starting on the first day of 3 consecutive recorded days with a Ambrosia artemisiifolia pollen count of $\geq 10$ grains $/ \mathrm{m}^{3}$ and ending on the last day of the last 3 consecutive recorded days with a pollen count of $\geq 10$ grains $/ \mathrm{m}^{3}$. Peak RPS was the 15 consecutive recorded days within the RPS with the highest 15-day moving average pollen count.

\section{Study assessments}

Participants (or their guardians) self-recorded allergy symptoms and symptom-relieving medication use in a daily e-diary. The average total combined symptom and medication score (TCS) during the peak RPS was the primary endpoint. The TCS is the sum of the 
average rhinoconjunctivitis daily symptom score (DSS) and average rhinoconjunctivitis daily medication score (DMS). The key secondary endpoints were the TCS during the entire RPS, DSS during the peak RPS, and DMS during the peak RPS. DSS and DMS during the entire RPS were also evaluated. The DSS was calculated from participant (or guardian) daily scoring of 6 rhinoconjunctivitis symptoms (runny nose, stuffy nose, sneezing, itchy nose, itchy eyes, and watery eyes) on a scale of 0 (no symptoms) to 3 (severe symptoms) and DMS was calculated based on participant (or guardian) recording of symptom-relieving medication use (Additional file 1: Table S1).

Safety was assessed by monitoring of adverse events (AEs) and by participant (or guardian) recording of solicited and pre-selected local AEs [17] that occurred within the first $60 \mathrm{~min}$ after treatment on a SLIT Report Card [18] for approximately the first 28 days of treatment. Percent compliance was calculated for each participant as the number of doses taken divided by the number of days between first tablet intake and date of last tablet intake. On average, treatment compliance in the trial was at least $90 \%$ for $73 \%$ of participants, and $98 \%$ were at least $75-90 \%$ compliant.

\section{Statistical analysis}

Post hoc analyses of the primary and key secondary efficacy endpoints were conducted in the subpopulation of Canadian participants in the Full Analysis Set (FAS), using the same statistical methods used for the full study population that were prespecified in the protocol. The FAS was defined as all participants who received at least one dose of study treatment and with at least one diary record during the peak RPS. Post hoc safety analysis was conducted in the subpopulation of Canadian participants in the AllSubjects-as-Treated dataset, defined as all randomized participants who received at least one dose of study treatment. Least square (LS) mean scores, differences in LS mean scores, and 2-sided 95\% CI for the efficacy endpoints were calculated using an analysis of variance (ANOVA) model which included fixed effects of treatment, baseline asthma status (yes/no), age group (5-11 years or 12-17 years), pollen season, and pollen region nested within pollen season. The percentage treatment differences in LS means with ragweed SLIT-tablet relative to placebo were calculated. Corresponding confidence intervals were calculated by the bootstrap method using 10,000 iterations. No missing data were imputed. Statistical analyses were conducted using SAS version 9.4 (Cary, NC).

\section{Results}

Participants

Of the total 1025 participants randomized, 246 of the participants were Canadian (24\% of the entire study population) and were analyzed in the safety population, and 223 completed the trial and were included in the FAS (Fig. 1). Discontinuation rates in the Canadian subpopulation were $14.7 \%$ with the ragweed SLIT-tablet and $4.6 \%$ with placebo (Fig. 1).

Baseline demographics and clinical characteristics in the Canadian subpopulation were well balanced between the treatment groups (Table 1) and were similar to the total study population [16]. The majority of Canadian participants were male $(58.9 \%)$ and white $(87.8 \%)$; the mean age was 12.4 years and $60.6 \%$ were aged 12 to 17 years. Asthma was reported in $35.8 \%$ of participants and most $(90.7 \%)$ were polysensitized. The majority $(82.5 \%)$ of Canadian participants had allergic rhinoconjunctivitis, whereas $17.5 \%$ had only allergic rhinitis.

\section{Ragweed pollen seasons}

In Canada, the mean (SD) Ambrosia artemisiifolia pollen counts in 2016, 2017, and 2018 during the peak RPS were 70 (36) grains $/ \mathrm{m}^{3}, 66(24)$ grains $/ \mathrm{m}^{3}$, and 109 (47) grains/ $\mathrm{m}^{3}$, respectively, and during the entire RPS were 43 (19) grains $/ \mathrm{m}^{3}, 44(14)$ grains $/ \mathrm{m}^{3}$, and $68(28)$ grains $/ \mathrm{m}^{3}$.

\section{Average daily TCS}

In the total study population, relative TCS (95\% CI) improvement with ragweed SLIT-tablet versus placebo was $-38.3 \% \quad(-46.0 \%,-29.7 \%$; LS mean difference, $-2.73 ; \quad \mathrm{P}<0.001)$ during peak RPS. In the Canadian subpopulation, relative TCS (95\% CI) improvement with ragweed SLIT-tablet compared with placebo was $-40.8 \%(-54.5 \%,-20.2 \%$; Fig. 2), with a LS mean score difference of $-1.59(\mathrm{P}=0.001$; Table 2) during peak RPS. Average TCS during the entire RPS improved with ragweed SLIT-tablet compared with placebo by $-36.6 \%(-50.2 \%,-16.5 \%$; Fig. 2$)$, with a LS mean score difference of $-1.36(\mathrm{P}=0.002$; Table 2$)$.

\section{Average daily DSS and DMS}

During peak RPS in the Canadian subpopulation, DSS and DMS (95\% CI) were improved with ragweed SLIT-tablet compared with placebo by $-30.6 \%(-45.2 \%,-7.7 \%$; LS mean difference, $-0.94 ; \quad \mathrm{P}=0.010)$ and $-77.2 \%$ $(-97.5 \%,-44.2 \%$; LS mean difference, $-0.66 ; \mathrm{P}=0.003)$, respectively (Fig. 3 and Table 2). In all, $85.9 \%$ of Canadian participants receiving ragweed SLIT-tablet and 71.8\% of participants receiving placebo had no symptomrelieving medication use (DMS $=0$ ) during the peak RPS. 


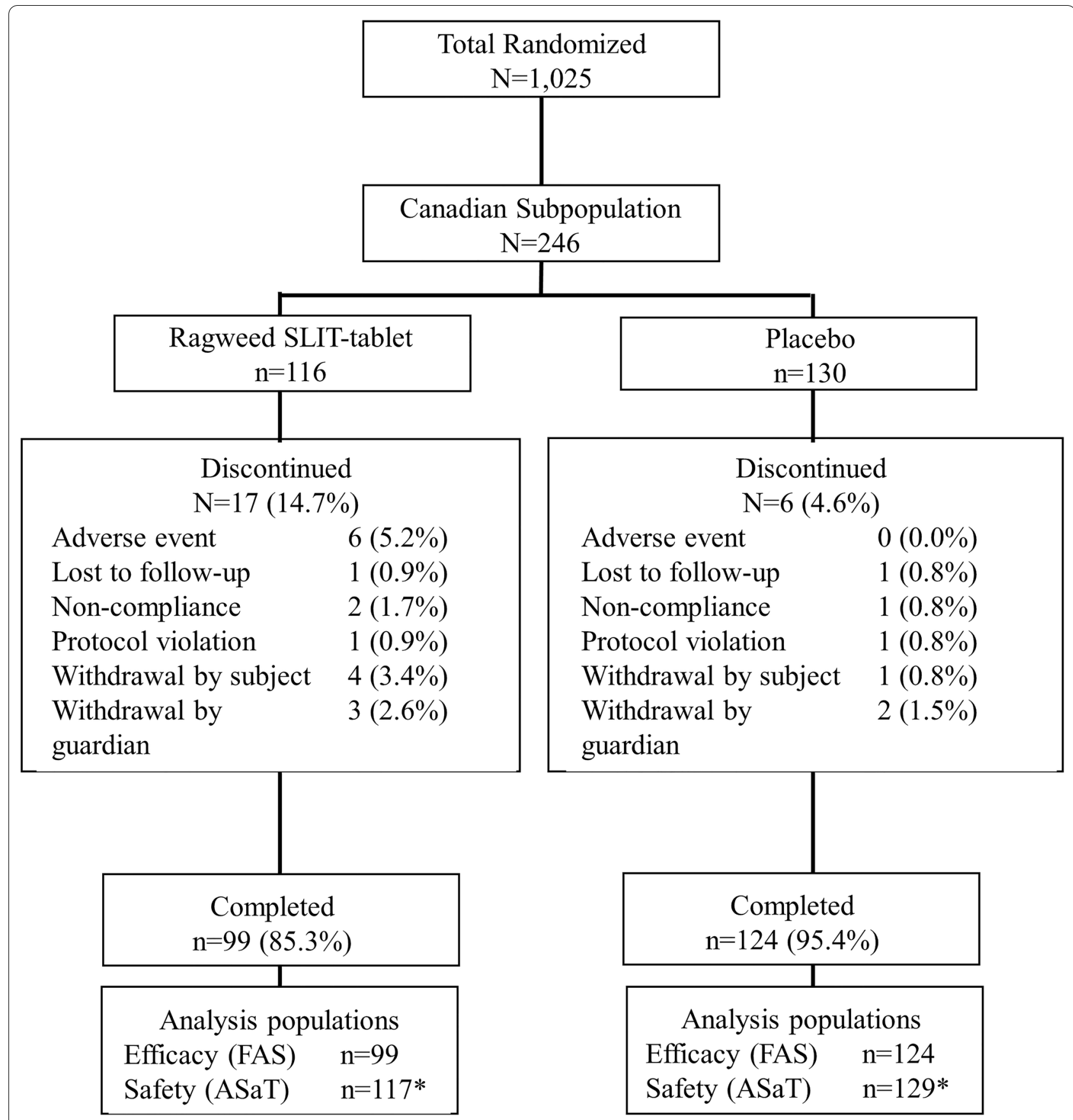

Fig. 1 Subject disposition in the Canadian subpopulation. ASaT, all subjects as treated; FAS, full analysis set; SLIT, sublingual immunotherapy. ${ }^{*}$ One subject randomized to placebo received the ragweed SLIT-tablet by mistake

Significant relative improvements in DSS and DMS were also observed during the entire RPS (Table 2).

\section{Safety}

AEs were monitored until 14 days after the end of the trial. The ragweed SLIT-tablet was well tolerated in the overall population and Canadian subpopulation, with no deaths, anaphylaxis events, or intramuscular epinephrine administrations related to ragweed SLITtablet treatment. There were also no severe events of ragweed SLIT-tablet-related local swellings of the mouth or throat, systemic allergic reactions, or asthma events. There were no reported events of eosinophilic esophagitis. The rate of discontinuation with ragweed 
Table 1 Baseline characteristics and demographics of randomized participants in the Canadian subpopulation

\begin{tabular}{|c|c|c|}
\hline & $\begin{array}{l}\text { Ragweed SLIT-Tablet } \\
(\mathrm{n}=116)\end{array}$ & $\begin{array}{l}\text { Placebo } \\
(n=130)\end{array}$ \\
\hline Male, n (\%) & $67(57.8)$ & $78(60.0)$ \\
\hline Age, mean (SD) y & $12.5(3.2)$ & $12.4(3.2)$ \\
\hline$<12 \mathrm{y}, \mathrm{n}(\%)$ & $46(39.7)$ & $51(39.2)$ \\
\hline$\geq 12 y, n(\%)$ & $70(60.3)$ & $79(60.8)$ \\
\hline White, n (\%) & $101(87.1)$ & $115(88.5)$ \\
\hline Participants with asthma, n (\%) & $38(32.8)$ & $50(38.5)$ \\
\hline \multicolumn{3}{|l|}{ IgE sensitization type, $n(\%)$} \\
\hline Ragweed only & $9(7.8)$ & $14(10.8)$ \\
\hline Ragweed and other allergens & $107(92.2)$ & $116(89.2)$ \\
\hline Alder tree & $68(58.6)$ & $74(56.9)$ \\
\hline Alternaria tenuis & $47(40.5)$ & $47(36.2)$ \\
\hline Birch tree & $74(63.8)$ & $81(62.3)$ \\
\hline Cat dander & $74(63.8)$ & $94(72.3)$ \\
\hline Cladosporium herbarum & $28(24.1)$ & $26(20.0)$ \\
\hline Dog dander & $64(55.2)$ & $80(61.5)$ \\
\hline House dust mites & $48(41.4)$ & $60(46.2)$ \\
\hline Mugwort & $65(56.0)$ & $78(60.0)$ \\
\hline Timothy grass & $70(60.3)$ & $85(65.4)$ \\
\hline A artemisiifolia SPT wheal size, mean (SD) mm & $10.2(3.0)$ & $10.5(3.5)$ \\
\hline A artemisiifolia serum specific $\lg \mathrm{E}$, mean (SD) $\mathrm{k} \mathrm{A}_{\mathrm{A}} / \mathrm{L}$ & $17.7(21.5)$ & $20.5(26.1)$ \\
\hline
\end{tabular}

SLIT sublingual immunotherapy, SPT skin prick test

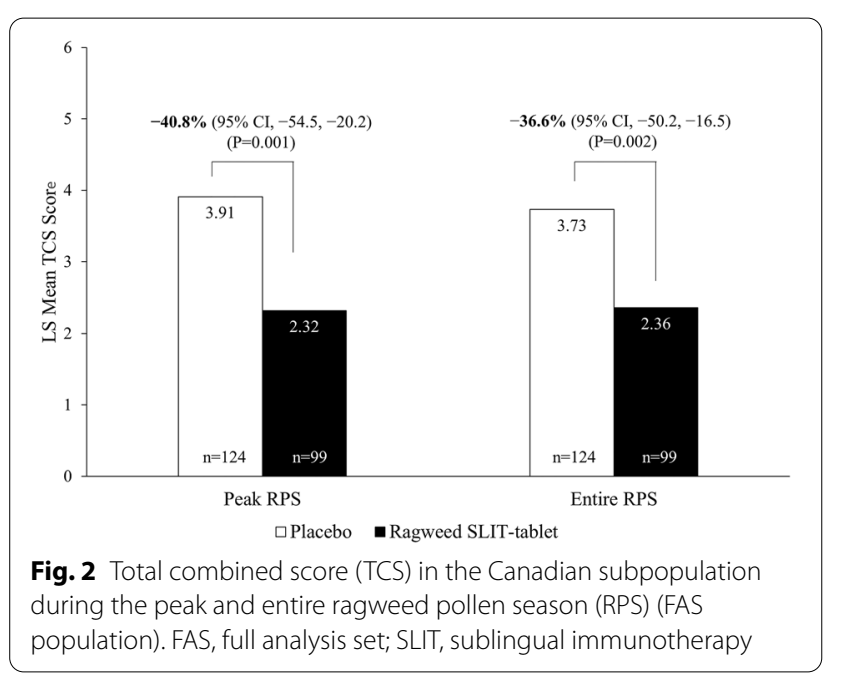

SLIT-tablet due to AEs in the Canadian subpopulation was $5.1 \%$ with the ragweed SLIT-tablet and $0.0 \%$ with placebo (Table 3).

In addition to $\mathrm{AE}$ monitoring, the occurrence of specific local AEs was actively solicited in the SLIT Report Card. Treatment-related AEs in the Canadian subpopulation were reported by $76.1 \%$ of participants receiving ragweed SLIT-tablet and $36.4 \%$ of participants receiving placebo (Table 3). No serious treatment-related AEs were reported in the Canadian subpopulation (Table 3), although 2 serious AEs related to ragweed SLIT-tablet occurred in the overall study population and have been previously described [16]. One Canadian participant experienced a mild, non-serious systemic allergic reaction (skin pruritus, redness, eye swelling/ pruritus, sneezing, runny nose) beginning on day 6 and discontinued the study on day 34. Additional details of this systemic allergic reaction have been previously described [16].

\section{Discussion}

The results of this post hoc analyses indicate that the ragweed SLIT-tablet improved symptoms and reduced symptom-relieving medication use in Canadian children and adolescents with AR/C during the peak and entire RPS. The efficacy and tolerability of the ragweed SLITtablet in the subpopulation of Canadian participants was consistent with the full study population that included participants from North America and Europe. Clinically meaningful benefit of the ragweed SLIT-tablet in the Canadian subpopulation was demonstrated, with a $40.8 \%$ improvement in the TCS over placebo during the peak RPS, despite the allowed use of symptom-relieving rescue medications in both the active and placebo groups. The 
Table 2 Total combined score (TCS), daily symptom score (DSS), and daily medication score (DMS) in the Canadian subpopulation during the peak and entire ragweed pollen season (FAS population)

\begin{tabular}{|c|c|c|c|c|}
\hline \multirow[b]{2}{*}{ Scale } & \multicolumn{2}{|c|}{ Peak ragweed pollen season } & \multicolumn{2}{|c|}{ Entire ragweed pollen season } \\
\hline & Ragweed SLIT-tablet & Placebo & Ragweed SLIT-tablet & Placebo \\
\hline TCS, LS mean & 2.32 & 3.91 & 2.36 & 3.73 \\
\hline $\mathrm{n}$ & 99 & 124 & 99 & 124 \\
\hline Difference vs placebo $(95 \% \mathrm{Cl})$ & $-1.59(-2.54,-0.65)$ & - & $-1.36(-2.21,-0.51)$ & - \\
\hline Reduction vs placebo, \% (95\% Cl) & $-40.8(-54.5,-20.2)$ & - & $-36.6(-50.2,-16.5)$ & - \\
\hline P value & 0.001 & - & 0.002 & - \\
\hline DSS, LS mean & 2.12 & 3.06 & 2.12 & 2.89 \\
\hline$n$ & 99 & 125 & 99 & 125 \\
\hline Difference vs placebo $(95 \% \mathrm{Cl})$ & $-0.94(-1.65,-0.22)$ & - & $-0.77(-1.43,-0.11)$ & - \\
\hline Reduction vs placebo, $\%(95 \%$ Cl) & $-30.6(-45.2,-7.7)$ & - & $-26.6(-41.6,-3.9)$ & - \\
\hline$P$ value & 0.010 & - & 0.022 & - \\
\hline DMS, LS mean & 0.20 & 0.86 & 0.24 & 0.84 \\
\hline $\mathrm{n}$ & 99 & 124 & 99 & 124 \\
\hline Difference vs placebo (95\% Cl) & $-0.66(-1.10,-0.23)$ & - & $-0.59(-0.95,-0.24)$ & - \\
\hline Reduction vs placebo, \% (95\% CI) & $-77.2(-97.5,-44.2)$ & - & $-70.8(-88.1,-43.5)$ & - \\
\hline P value & 0.003 & - & 0.001 & - \\
\hline
\end{tabular}

FAS full analysis set, LS least square, SLIT sublingual immunotherapy

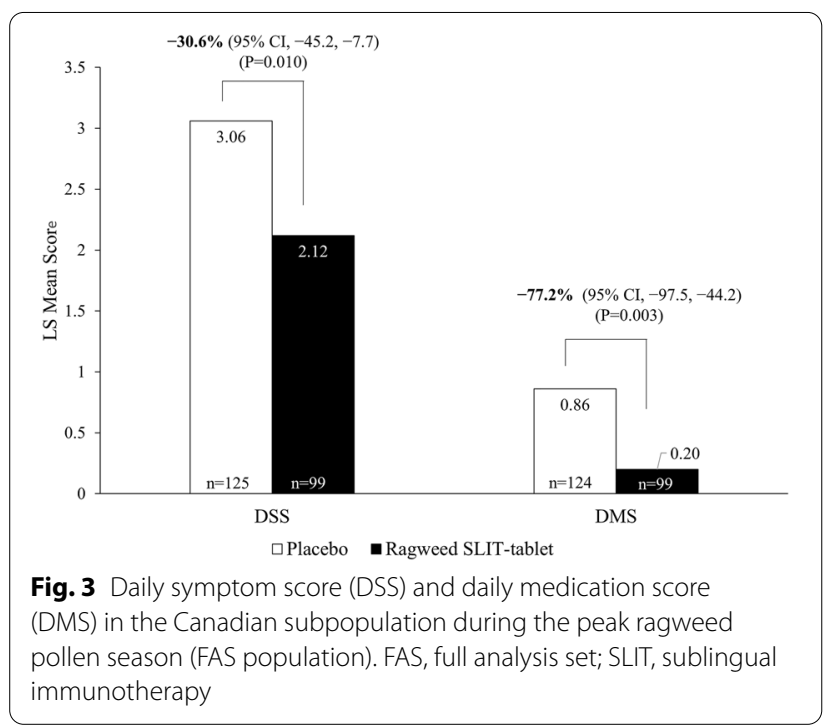

impressive reduction in the need for symptom-relieving rescue medication (DMS, $-77 \%$ ) during the peak season suggests that individuals with severe symptoms may show substantial clinical benefit from SLIT-tablet treatment. The magnitude of TCS improvement in the Canadian children and adolescents was similar to that of Canadian adults (39.5\%; $\mathrm{p}<0.0001$ vs placebo) in a post hoc analysis of 2 adult ragweed SLIT-tablet trials. [15].

The overall safety profile was similar between the Canadian subpopulation and the total study population.
The proportion of Canadian participants with treatmentemergent or treatment-related AEs $(92.3 \%$ and $76.1 \%$, respectively) in the ragweed SLIT-tablet group was also comparable to that in the Canadian adult subpopulation (94.5\% and $80.9 \%$, respectively) [15]. The rates of AEs were slightly higher during the trial than for most previous trials of SLIT-tablets in both the placebo and ragweed-SLIT-tablet groups, which is most likely because of the use of the SLIT Report Card. The SLIT Report Card is a questionnaire that actively solicits the patient-reported occurrence of specific local AEs that are commonly associated with SLIT [18] and its use has been shown to increase the frequency of many of these AEs compared with standard, open-ended AE reporting used in previous SLIT-tablet trials [19]. Practically, AEs did not appear to be particularly problematic for participants as the proportion of Canadian children and adolescents receiving the ragweed SLIT-tablet who discontinued due to treatment-related AEs was $5.1 \%$. This rate is lower than that observed in Canadian adults receiving the ragweed SLIT-tablet (12.7\%) [15] and is similar to rates of discontinuation observed with grass and house dust mite SLIT-tablet [20]. The majority of the remaining discontinuations in the ragweed SLIT-tablet group in the Canadian participants were withdrawals by the subject or guardian. Importantly, approximately a third of the Canadian subpopulation had mild to moderate stable asthma, yet there were no severe asthma events.

A strength of this analysis is the large size of the analyzed subpopulation. The trial was the largest 
Table 3 Safety summary in the Canadian subpopulation (All-Subjects-as-Treated)

\begin{tabular}{|c|c|c|}
\hline AE, No. (\%) & $\begin{array}{l}\text { Ragweed SLIT-tablet } \\
(\mathrm{n}=117)^{*}\end{array}$ & $\begin{array}{l}\text { Placebo } \\
(n=129)^{*}\end{array}$ \\
\hline Treatment-emergent AE & $108(92.3)$ & $96(74.4)$ \\
\hline Treatment-related AE & $89(76.1)$ & $47(36.4)$ \\
\hline SAE & 0 & 0 \\
\hline Treatment-related SAE & 0 & 0 \\
\hline AE leading to treatment discontinuation & $6(5.1)$ & 0 \\
\hline Treatment-related AE leading to treatment discontinuation & $6(5.1)$ & 0 \\
\hline Discontinued treatment due to SAE & 0 & 0 \\
\hline Discontinued treatment due to a treatment-related SAE & 0 & 0 \\
\hline
\end{tabular}

$A E$ adverse event, $S A E$ serious adverse event

* One subject randomized to placebo received the ragweed SLIT-tablet by mistake

pediatric SLIT-tablet trial conducted to date and therefore provided opportunity for robust subpopulation analyses. Even within this smaller subpopulation, the improvement in TCS met the various definitions of a clinically meaningful effect, including those of regulatory agencies and professional organizations [21, 22]. The results and conclusions from this post hoc analysis are limited to those in the Canadian subpopulation and cannot be generalized to other regional subpopulations.

The ability to deliver the ragweed SLIT-tablet at home may be ideal for children, adolescents, and caregivers for whom it may be difficult to schedule office visits for SCIT administration around school and work schedules and also for those who live in remote areas. In addition, patients may have negative feelings about injections, which are avoided with the use of the SLIT-tablet [10] Thus, the efficacy and tolerability demonstrated in the current analysis support the use of the ragweed SLITtablet in Canadian children and adolescents with AR/C as an alternative to SCIT.

\section{Abbreviations}

AE: Adverse event; AR/C: Allergic rhinitis with or without conjunctivitis; DMS: Daily medication score; DSS: Daily symptom score; RPS: Ragweed pollen season; SCIT: Subcutaneous immunotherapy; SLIT: Sublingual immunotherapy; TCS: Total combined score.

\section{Supplementary Information}

The online version contains supplementary material available at https://doi. org/10.1186/s13223-021-00626-2.

Additional file 1: Table S1. Scoring of symptoms and medication use.

\section{Acknowledgements}

Medical writing and editorial assistance were provided by Erin P. Scott, PhD, of Scott Medical Communications, LLC. This assistance was funded by ALK, Bedminster, NJ.

\section{Authors' contributions}

DIB contributed to the acquisition of the data, interpretation of the data, review of the manuscript, and approved the submitted version. AKE contributed to the acquisition of the data, interpretation of the data, review of the manuscript, and approved the submitted version. RG contributed to the acquisition of the data, interpretation of the data, review of the manuscript, and approved the submitted version. HN contributed to the design of the work, interpretation of the data, review of the manuscript, and approved the submitted version. All authors have read and approved the final manuscript.

Funding

This trial was funded by Merck Sharp \& Dohme Corp., a subsidiary of Merck \& Co., Inc., Kenilworth, NJ, USA. This post hoc analysis was funded by ALK-Abelló A/S, Hørsholm, Denmark. Medical writing and editorial assistance were funded by ALK, Bedminster, NJ.

\section{Availability of data and materials}

All data generated or analyzed during this study are included within this published article (and its Additional file 1).

\section{Declarations}

\section{Ethics approval and consent to participate}

The study was approved by each sites' Institutional Review Board. The guardians of each participant provided written informed consent before the participant started the trial.

\section{Consent for publication}

Not applicable.

\section{Competing interests}

D.I. Bernstein has received grant support from Aimmune, Allergy Therapeutics, ALK, Amgen, AstraZeneca, Avillion, Biocryst, Boehringer Ingelheim, Cipla, Genentech, GlaxoSmithKline, Gossamer, Leo, Lupin, Menlo, Merck, Mylan, Novartis, Novum, Pearl, Regeneron, Shire, and TEVA, served as an advisor for ALK America, Gerson-Lehman, GlaxoSmithKline, and Guidepoint Global, and been a speaker for ALK and GlaxoSmithKline. A.K. Ellis has participated in advisory boards for Abbvie, ALK-Abelló, AstraZeneca, Aralez, Bausch Health, Circassia Ltd, GlaxoSmithKline, LEO Pharma, Johnson \& Johnson, Merck, Mylan, Novartis, Pediapharm and Pfizer, has been a speaker for ALK, Aralez, AstraZeneca, Bausch Health, Boehringer-Ingelheim, CACME, Meda, Medexus, Mylan, Merck, Novartis, Pediapharm, Pfizer, The ACADEMY, and Takeda. Her institution has received research grants from AstraZeneca, Bayer, LLC, Circassia Ltd, Green Cross Pharmaceuticals, GlaxoSmithKline, Sun Pharma, Merck, Novartis, Pfizer, Regeneron and Sanofi. She has also served as an independent consultant to Allergy Therapeutics, Bayer, LLC, Ora Inc., and Regeneron in the past. R. Gagnon has served as a speaker and/or advisor for ALK-Abello, AstraZeneca, Aralez, CSL Behring, GlaxoSmithKline, Merck, 
Novartis, Pediapharm, Pfizer, Sanofi, and Shire, and served as an investigator for AstraZeneca, Biocryst, DBV, GlaxoSmithKline, Green Cross Pharmaceuticals, Merck, Novartis, Regeneron, Shire, Stallergenes, and Sanofi Genzyme/ Regeneron. H. Nolte is an employee of ALK.

\section{Author details}

'Division of Allergy \& Immunology, Department of Medicine, Queen's University, Kingston, ON, Canada. ${ }^{2}$ Clinique Spécialisée en Allergie de La Capitale, Québec, QC, Canada. ${ }^{3}$ Division of Immunology, Allergy and Rheumatology, University of Cincinnati College of Medicine and Bernstein Clinical Research Center, Cincinnati, OH, USA. ${ }^{4}$ ALK, Bedminster, NJ, USA.

Received: 20 July 2021 Accepted: 15 November 2021

Published online: 09 December 2021

\section{References}

1. Meltzer EO, Blaiss MS, Derebery MJ, et al. Burden of allergic rhinitis: results from the pediatric allergies in America survey. J Allergy Clin Immunol. 2009;124:S43-70.

2. Meltzer EO, Farrar JR, Sennett C. Findings from an online survey assessing the burden and management of seasonal allergic rhinoconjunctivitis in US patients. J Allergy Clin Immunol Pract. 2017;5:779-789 e6.

3. Salo PM, Calatroni A, Gergen PJ, et al. Allergy-related outcomes in relation to serum IgE: results from the national health and nutrition examination survey 2005-2006. J Allergy Clin Immunol. 2011;127:1226-35 e7.

4. Burbach GJ, Heinzerling LM, Rohnelt C, et al. Ragweed sensitization in Europe-GA(2)LEN study suggests increasing prevalence. Allergy. 2009;64:664-5.

5. Chan-Yeung M, Anthonisen NR, Becklake MR, et al. Geographical variations in the prevalence of atopic sensitization in six study sites across Canada. Allergy. 2010;65:1404-13.

6. Salo PM, Arbes SJ Jr, Jaramillo R, et al. Prevalence of allergic sensitization in the United States: results from the National Health and Nutrition Examination Survey (NHANES) 2005-2006. J Allergy Clin Immunol. 2014;134:350-9.

7. Dykewicz MS, Wallace DV, Amrol DJ, et al. Rhinitis 2020: a practice parameter update. J Allergy Clin Immunol. 2020;146:721-67.

8. Valovirta E, Petersen TH, Piotrowska T, et al. Results from the 5-year SQ grass sublingual immunotherapy tablet asthma prevention (GAP) trial in children with grass pollen allergy. J Allergy Clin Immunol. 2018;141:529-38.

9. Jacobsen L, Niggemann B, Dreborg S, et al. Specific immunotherapy has long-term preventive effect of seasonal and perennial asthma: 10-year follow-up on the PAT study. Allergy. 2007;62:943-8.

10. Chester JG, Bremberg MG, Reisacher WR. Patient preferences for route of allergy immunotherapy: a comparison of four delivery methods. Int Forum Allergy Rhinol. 2016;6:454-9.

11. Calderon MA, Simons FE, Malling $H J$, et al. Sublingual allergen immunotherapy: mode of action and its relationship with the safety profile. Allergy. 2012;67:302-11.

12. Canonica GW, Cox L, Pawankar R, et al. Sublingual immunotherapy: World Allergy Organization position paper 2013 update. World Allergy Organ J. 2014;7:6.

13. Creticos PS, Maloney J, Bernstein DI, et al. Randomized controlled trial of a ragweed allergy immunotherapy tablet in North American and European adults. J Allergy Clin Immunol. 2013;131:1342-9 e6.

14. Nolte H, Hebert J, Berman G, et al. Randomized controlled trial of ragweed allergy immunotherapy tablet efficacy and safety in North American adults. Ann Allergy Asthma Immunol. 2013;1 10:450-456 e4.

15. Kim H, Waserman S, Hébert J, et al. Efficacy and safety of ragweed sublingual immunotherapy in Canadian patients with allergic rhinoconjunctivitis. Allergy Asthma Clin Immunol. 2014;10:55

16. Nolte H, Bernstein DI, Nelson HS, et al. Efficacy and safety of ragweed SLIT-tablet in children with allergic rhinoconjunctivitis in a randomized, placebo-controlled trial. J Allergy Clin Immunol Pract. 2020;8:2322-2331 e5.

17. Passalacqua G, Baena-Cagnani CE, Bousquet J, et al. Grading local side effects of sublingual immunotherapy for respiratory allergy: speaking the same language. J Allergy Clin Immunol. 2013;132:93-8.
18. Norquist J, Flood E, Tanzosh T, et al. Development of a report card for identifying local sublingual immunotherapy events in clinical trials. Patient. 2017;10:439-46.

19. Nolte H, Bernstein DI, Sussman GL, et al. Impact of adverse event solicitation on the safety profile of sq house dust mite sublingual immunotherapy tablet. J Allergy Clin Immunol Pract. 2018;6:2081-2086. e1.

20. Bernstein DI, Bardelas JA Jr, Svanholm Fogh B, et al. A practical guide to the sublingual immunotherapy tablet adverse event profile: implications for clinical practice. Postgrad Med. 2017. https://doi.org/10.1080/00325 481.2017.1302306.

21. Nelson HS, Calderon MA, Bernstein DI, et al. Allergen immunotherapy clinical trial outcomes and design: working toward harmonization of methods and principles. Curr Allergy Asthma Rep. 2017;17:18.

22. Canonica GW, Baena-Cagnani CE, Bousquet J, et al. Recommendations for standardization of clinical trials with allergen specific immunotherapy for respiratory allergy. A statement of a World Allergy Organization (WAO) taskforce. Allergy. 2007;62:317-24

\section{Publisher's Note}

Springer Nature remains neutral with regard to jurisdictional claims in published maps and institutional affiliations.

Ready to submit your research? Choose BMC and benefit from:

- fast, convenient online submission

- thorough peer review by experienced researchers in your field

- rapid publication on acceptance

- support for research data, including large and complex data types

- gold Open Access which fosters wider collaboration and increased citations

- maximum visibility for your research: over $100 \mathrm{M}$ website views per year

At BMC, research is always in progress.

Learn more biomedcentral.com/submissions 